\section{A Fatal Case of Calciphylaxis in a Patient with Systemic Lupus Erythematosus and Normal Renal Function}

\section{To the Editor:}

Calciphylaxis is a rare condition that involves cutaneous microvascular calcification leading to thrombosis and occlusion. Initial lesions appear violaceous and progress to non-healing necrotic ulcerations ${ }^{1}$. One-year mortality is over $50 \%$, with sepsis as the leading cause of death ${ }^{1}$. Calciphylaxis is well described in patients with endstage renal disease with abnormalities in the calcium-phosphate-parathyroid hormone (PTH) axis ${ }^{2}$. An increasing number of case reports describe calciphylaxis in the absence of renal impairment associated with connective tissue disease, primary hyperparathyroidism, malignancy, liver disease, and protein $\mathrm{C}$ or $\mathrm{S}$ deficiencies ${ }^{3}$. We describe a case of rapidly progressive nonuremic calciphylaxis in a patient with systemic lupus erythematosus (SLE) and highlight the importance of calciphylaxis in the differential diagnosis of cutaneous ulceration.

Our patient was a 77-year-old white woman with a 20-year history of SLE with features of arthritis, positive antinuclear antibody (ANA), hypocomplementemia, pulmonary involvement, and Raynaud disease. Her immunosuppressive regimen included azathioprine and hydroxychloroquine. Her comorbidities included type II diabetes, recurrent venous thromboembolism treated with warfarin for over 10 years, coronary artery disease, pulmonary hypertension, and congestive heart failure.

She presented to the clinic with a 1-day history of calf pain and erythema. On admission, her INR was therapeutic and Doppler vein ultrasound demonstrated a superficial venous thrombus. Within days, violaceous ulcerations developed on both calves, with progressive areas of necrosis (Figure 1). She developed bullous lesions over several lower extremity digits. Because of concerns about evolving vasculitis, she was prescribed high-dose steroids.

Investigations showed a positive ANA with elevated anticentromere antibodies. Erythrocyte sedimentation rate was $85 \mathrm{~mm} / \mathrm{h}$. There were normal levels of anti-dsDNA, complement factor 3 (C3), cryoglobulins, protein S free antigen, SLE-sensitive partial thromboplastin time, dilute Russell's viper venom time, and creatinine. C4 (0.08 g/l) was low. Serum calcium (2.00 $\mathrm{mmol} / \mathrm{l})$, albumin $(28 \mathrm{~g} / \mathrm{l})$, and 25-hydroxy vitamin D (42 nmol/l) were low. The patient had a mildly elevated PTH (11.6 pmol/1; normal range 1.3-7.6 $\mathrm{pmol} / \mathrm{l})$. Anticardiolipin antibodies were negative. Protein C activity was 0.44 $\mathrm{U} / \mathrm{ml}$ (normal $0.73-1.50 \mathrm{U} / \mathrm{ml}$ ); however, the patient was taking warfarin. Radiographs showed vascular calcification in the lower extremities.

A full-thickness skin biopsy was done. Rather than the expected vasculitis, microscopy demonstrated vascular calcification, necrosis, and acute inflammation highly suggestive of calciphylaxis (Figure 2).

Warfarin was changed to unfractionated heparin and prednisone was tapered. Vitamin D was started with eventual normalization of PTH. Despite aggressive wound care, the lesions progressed and she developed extensive gangrene. Hyperbaric oxygen was contraindicated owing to poor cardiac function. Sodium thiosulfate was initiated at a dose of $25 \mathrm{~g}$ intravenously 3 times per week. Pain improved after 1 week of treatment but the medication was discontinued as a result of profound metabolic acidosis. She died 3 months after admission from sepsis.

Nonuremic calciphylaxis is rare but is reported in a variety of autoimmune conditions, where it is often misdiagnosed as vasculitis ${ }^{4}$. Its clinical presentation also bears similarities to warfarin skin necrosis and antiphospholipid antibody syndrome. Lesions typically involve the lower extremities and regions with higher adiposity such as the thighs, buttocks, or abdomen ${ }^{2}$.

High mortality, rapid progression, and differences in treatment approaches necessitate early diagnosis. To our knowledge, there are only 2 prior case reports of calciphylaxis in patients with SLE and normal renal function $^{5,6}$. Aliaga and Barreira described a young woman with active SLE and biopsy showing both leukocytoclastic vasculitis and calciphylaxis that was rapidly fatal despite high-dose steroids and immunosuppression ${ }^{5}$. Here we demonstrate that nonuremic calciphylaxis can occur in the absence of clinically active SLE, and in this context requires a distinct treatment approach. Although the role of corticosteroids in the natural history of calci- phylaxis is controversial, it is considered a risk factor and is generally not recommended therapeutically.

Predisposing risk factors include female sex, obesity, diabetes, elevated calcium-phosphate product, and systemic corticosteroid use. Warfarin is theoretically implicated as it impairs the carboxylation of proteins that inhibit vascular calcification, but epidemiological studies are conflicting ${ }^{1}$.

Imaging modalities such as ultrasound and computed tomography angiography can be used to rule out contributing peripheral vascular disease. Vascular calcification on plain radiographs can be seen in extreme cases ${ }^{7}$. Deep incisional biopsy confirms the diagnosis of calciphylaxis; however, it carries significant risk of further tissue damage and impaired wound healing. Biopsy shows areas of necrosis with arterial medial calcification, subintimal fibrosis, and vascular thrombosis ${ }^{1}$.

Evidence-based treatments are lacking because of poor understanding of the mechanisms and low prevalence. In addition to excellent wound care, sodium thiosulphate and bisphosphonates are described treatments in patients with SLE and renal disease, but application in cases of nonuremic calciphylaxis is limited to case reports ${ }^{8,9}$. To our knowledge, this is the first report of its use in a patient with SLE and nonuremic calciphylaxis.

Nonuremic calciphylaxis is rare but can progress rapidly, with devastating outcomes. Its presentation shares many similarities with vasculitis and should be considered in the differential diagnosis, particularly when additional risk factors are present.

ELISABETH ANNA PEK, MD, Department of Medicine, University of Toronto; PAMELA LAYA JOSEPH, MD, Division of Physical Medicine and Rehabilitation, Department of Medicine, University of Toronto; AYMAN SAEED AL HABEEB, MBBS, FRCPC, Department of Laboratory Medicine and Pathobiology, University Health Network; LORI JOANNA ALBERT, MD, FRCPC, Division of Rheumatology, Department of Medicine, University Health Network, Toronto, Ontario, Canada.

Dr. Pek and Dr. Joseph contributed equally to the preparation of this manuscript.

Address correspondence to Dr. L.J. Albert, Division of Rheumatology, Department of Medicine, Toronto Western Hospital, 399 Bathurst St., 1E - 424, Toronto, Ontario M5T 2S8, Canada.E-mail: lori.albert@uhn.ca

\section{REFERENCES}

1. Weenig RH, Sewell LD, Davis MD, McCarthy JT, Pittelkow MR. Calciphylaxis: natural history, risk factor analysis, and outcome. J Am Acad Dermatol 2007;56:569-79.

2. Budisavljevic MN, Cheek D, Ploth DW. Calciphylaxis in chronic renal failure. J Am Soc Nephrol 1996;7:978-82.

3. Nigwekar SU, Wolf M, Sterns RH, Hix JK. Calciphylaxis from nonuremic causes: a systematic review. Clin J Am Soc Nephrol 2008;3:1139-43.

4. Lee JL, Naguwa SM, Cheema G, Gershwin ME. Recognizing calcific uremic arteriolopathy in autoimmune disease: an emerging mimicker of vasculitis. Autoimmun Rev 2008;7:638-43.

5. Aliaga LG, Barreira JC. Calciphylaxis in a patient with systemic lupus erythematosus without renal insufficiency or hyperparathyroidism. Lupus 2012;21:329-31.

6. Zechlinski JJ, Angel JR. Calciphylaxis in the absence of renal disease: secondary hyperparathyroidism and systemic lupus erythematosus. J Rheumatol 2009;36:2370-1.

7. Li JZ, Huen W. Images in clinical medicine. Calciphylaxis with arterial calcification. N Engl J Med 2007;357:1326.

8. Mallett A, John G, Ranganathan D, Kark A, Berquier I, Casey J, et al. Sustained remission of systemic lupus erythematosus related calciphylaxis. Lupus 2012;21:441-4.

9. Wendroth SM, Heady TN, Haverstick DM, Bachmann LM, Scott MG, Boyd JC, et al. Falsely increased chloride and missed anion gap elevation during treatment with sodium thiosulfate. Clin Chim Acta 2014;431:77-9.

J Rheumatol 2016;43:2; doi:10.3899/jrheum.150819 

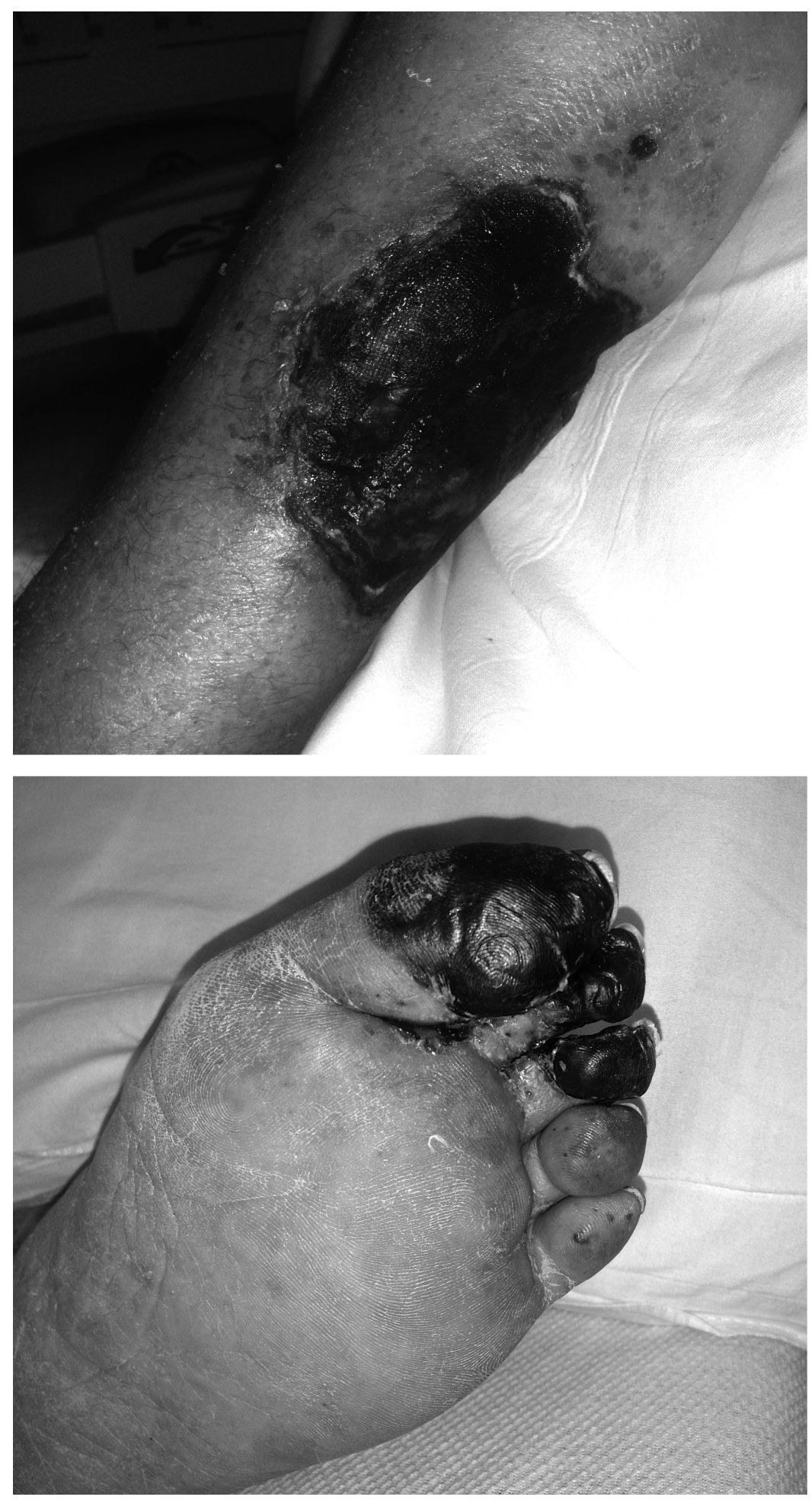

Figure 1. Calciphylaxis. Necrotic left leg and foot ulcerations. 


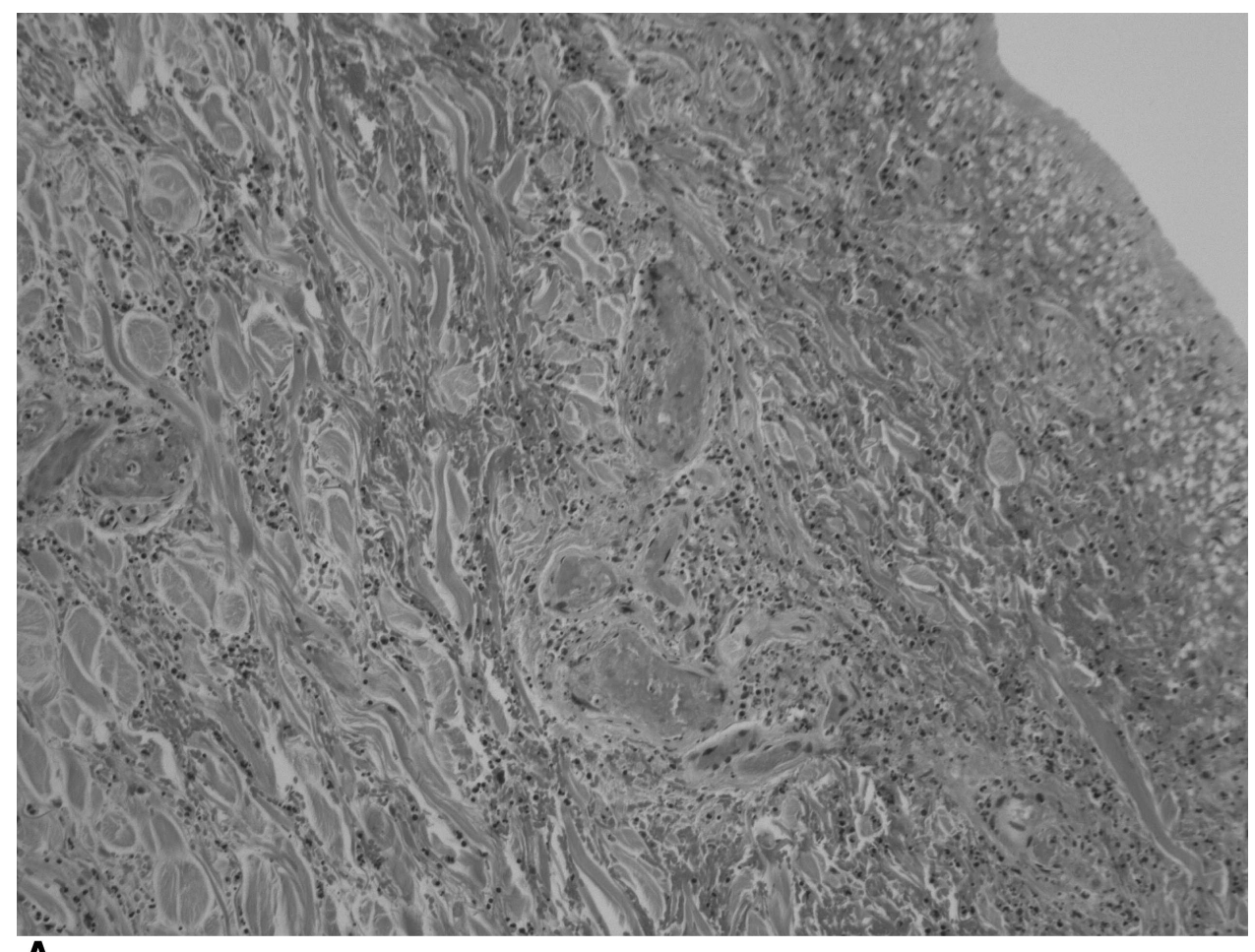

A

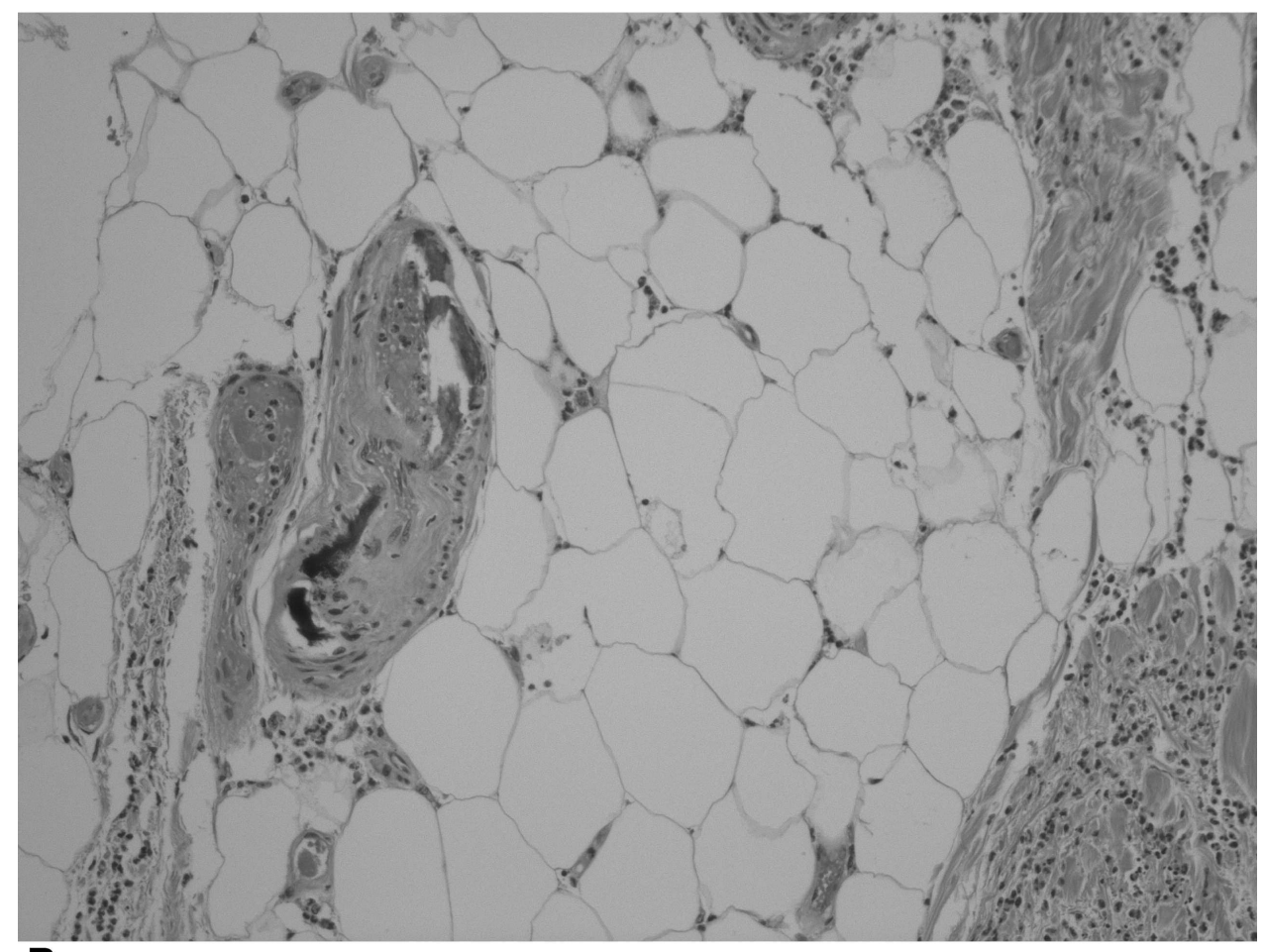

B

Figure 2. Histopathological study of the lower extremity lesions showing intravascular fibrin thrombi, medial calcification in the vessel walls, and pronounced neutrophilic infiltrate extending to the subcutaneous septa. A. Subcutaneous vessels with intramural fibrin thrombi with acute and chronic inflammation. B. Vessel with medial calcification and intramural fibrin. 